\title{
Práticas Vernaculares de Moderação Online em Grupos do Facebook
}

\author{
Vernacular Practices of Online Moderation in Facebook Groups \\ Prácticas vernáculas de moderación en línea em grupos de Facebook
}

\author{
Tarcízio Roberto da Silva \\ Universidade Federal do ABC - UFABC - São Paulo - Brasi \\ ORCID: https://orcid.org/0000-0002-7094-8708 \\ Endereço currículo Plataforma Lattes: http://lattes.cnpq.br/8992630383672112 \\ E-mail: eu@tarciziosilva.com.br
}

\begin{abstract}
Resumo: O debate sobre moderação online é central nos estudos propositivos sobre iniciativas públicas deliberativas. A literatura sobre a questão propôs critérios para mensuração da qualidade deliberativa dos ambientes, aplicadas na ideação e análise das iniciativas. $\mathrm{O}$ atual estudo se debruça sobre a multiplicação dos espaços digitais relativamente abertos, tais como mídias sociais, com fim de entender se e de que modo as práticas de definição de regras e moderação em comunidades online guardam similaridades emergentes com critérios deliberativos. O presente artigo discute a equivalência destes critérios a partir da análise dos textos de "Regras da Comunidade" em 15 grupos no Facebook sem fins deliberativos, identificando práticas que possuem aderência aos critérios Tópicos de Discussão e Respeito, porém recorrente evitação de dissensos ou controvérsias.
\end{abstract}

Palavras-chave: Moderação. Conversação online. Mídias sociais. Facebook.

\begin{abstract}
The debate on online moderation is central to propositional studies on deliberative public initiatives. The literature on the issue proposed criteria for measuring the deliberative quality of environments, applied in the analysis of initiatives. The current study focuses on the multiplication of relatively open digital spaces, such as social media, to understand whether and how the practices of defining rules and moderation in online communities shows similarities with deliberative criteria. The present article discusses the equivalence of these criteria based on the analysis of the texts of "Rules of the Community" in 15 groups on Facebook without deliberative purposes, identifying practices that adhere to the Topics of Discussion and Respect criteria, but also recurrent avoidance of dissent or controversy.
\end{abstract}

Keywords: Moderation. Online conversation. Deliberation. Social media. Facebook. 


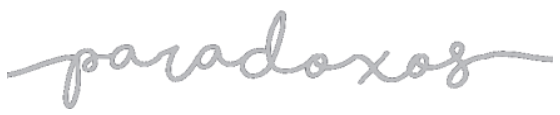

Práticas vernaculares de moderação Online em grupos do Facebook

SILVA, 2020

Resumen: El debate sobre la moderación en línea es fundamental para los estudios proposicionales sobre iniciativas públicas deliberativas. La literatura sobre el tema propuso criterios para medir la calidad deliberativa de los espacios em línea, aplicados en la ideación y el análisis de iniciativas. La investigacion se centra en la multiplicación de espacios digitales relativamente abiertos, como las redes sociales, para comprender si las prácticas de definición de reglas y moderación en las comunidades en línea mantienen similitudes emergentes con criterios deliberativos y de qué manera. El artículo discute la equivalencia de estos criterios basados en el análisis de los textos de "Reglas de la Comunidad" en 15 grupos en Facebook sin propósitos deliberativos, identificando prácticas que se adhieren a los criterios de Temas de Discusión y Respeto, pero recorrentemente evitan el disenso o controvérsia.

Palabras clave: Moderación. Conversación en línea. Deliberación. Redes sociales. Facebook.

\section{Conversação online e mídias digitais}

A chamada "liberação do polo emissor" (LEMOS, 2002) com a disseminação de tecnologias digitais de informação e comunicação como a internet, web comercial e barateamento dos computadores e dispositivos móveis como smartphones teve impactos em todas esferas sociais, inclusive política - da vernacular à institucional. Segundo Penteado, Araújo e Pimentel, "as TICs também podem viabilizar a abertura de novos espaços de participação política, ampliando a inserção da sociedade civil” (2014, p.126). Do ponto de vista do debate sobre deliberação online, buscou-se entender como as tecnologias digitais poderiam ser uma janela ou campo potencializador de acesso à esfera pública. Gomes (2019, p.27) aponta cinco acepções correntes sobre esfera pública, a saber: esfera pública sobre domínio do que é público; como arena pública; como espaço público; como domínio discursivo aberto; e como interação social. Esta multiplicidade de considerações na literatura sobre esfera pública como fenômeno comunicacional-político complexifica-se com a disseminação das mídias híbridas, em que os cidadãos usam e habitam as mídias para além do duopólio de mídia de massa e imprensa (CHADWICK, DENNIS e SMITH, 2015).

A internet, deste modo, foi e é observada amplamente e de forma controversa sobre seu potencial de adequação ao debate público. Seria a internet um espaço habilitador de uma esfera pública mais próxima do caráter normativo proposto pelos estudiosos do tema? Esta “identificação com a ideia de esfera pública como um espaço, agora também configurado 


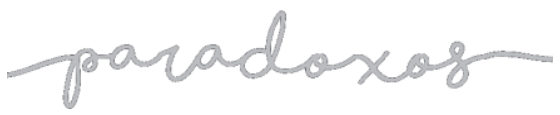

Práticas vernaculares de

moderação Online em grupos do Facebook

SILVA, 2020

virtualmente, orientado para a comunicação deliberativa livre entre seus membros" (SAMPAIO e BARROS, 2011, p.164) passa necessariamente pelo relativo empoderamento dos cidadãos na iniciação e participação em conversação pública e política.

Entretanto, através de décadas de estudo na temática, autores interessados em democracia digital perceberam as limitações efetivas de como o caráter distributivo da internet se desdobra em tecnologias reais como plataformas de mídias sociais. Entre sociedade civil e atores organizacionais da política institucional, as dificuldades em se criar espaços de decisão política efetiva passam por questões que dependem efetivamente das affordances sociotécnicas dos ambientes digitais entre materialidades, interface e modelos de negócios (BUCHER e HELMOND, 2016; ROSSINI, 2019).

A esfera civil em discussão de assuntos da seara política, porém, não deve ser descartada como inócua. Como aponta Gomes,

\begin{abstract}
Se não exerce diretamente a decisão política, a esfera civil, por outro lado, produz discursos, impressões, opiniões e até debates sobre a agenda política, aquilo que acho que podemos apropriadamente chamar de conversação civil. Não se esgota a conversação civil na noção de debate, de disputa, mas simplesmente a ideia de fala pública, de expressão, de publicação. O debate é apenas uma das espécies do gênero da conversação, que inclui ademais desde a fofoca até o jornalismo, passando por todas as formas de expressão discursiva sobre os negócios públicos (GOMES, 2019, p.28).
\end{abstract}

Debate, conversação, colaboração e conflitos enquanto práticas pervasivas nas mídias sociais podem ser vistas como capacidades relevantes para o cidadão interagente - e talvez haja um desdobramento na interação interpessoal sobre assuntos políticos. Os sites de redes sociais trazem diferentes tipos de conversas - do lúdico ao políticoinstitucional - para o cotidiano dos usuários, em um fluxo de trocas simbólicas que não necessariamente tem delimitações claras. Assim, acreditamos que entender as práticas conversacionais do cotidiano e os modos de coordenação entre número de indivíduos que não possuem relações afetivas prévias é relevante para a investigação sobre como as práticas de moderação são construídas em uma espécie de competência midiática informal em ambientes digitais. 


\section{Facebook e seus grupos: espaço de conversação e articulação?}

Sites de redes sociais foram definidos pela literatura acadêmica como um objeto cambiante. Ainda em voga, as características materiais dos ambientes quanto a potenciais de autoexpressão e circulação de conteúdos se destacam na literatura da Comunicação. Boyd (2010) atribui aos sites de redes sociais as seguintes características definidoras: possibilidade de criação de perfis públicos que representam pessoas físicas ou jurídicas; listas de "amigos" ou conexões análogas como "likes", "seguidores" ou "fãs"; e ferramentas para comunicação pública, tais como espaços de comentários, grupos e fóruns. Nos últimos anos, com a constatação da concentração midiática nestes ambientes regidos por algoritmos opacos (SILVEIRA, 2017) e plataformização (HELMOND, 2015), o conceito de "plataforma de mídia social" ganhou espaço para dar conta de como ecossistemas tecnomidiáticos como Facebook, Google e Amazon se tornaram espaços intermediários entre diferentes tipos de usuários/provedores e também fornecedores de tecnologias de rastreamento, cadastro e acesso a serviços.

Tais ambientes são objeto de debate sobre suas capacidades e affordances para diferentes tipos e modalidades de debate, consulta ou extração de informações sobre opinião pública, especialmente o Facebook - plataforma mais usada na maioria dos países do Hemisfério Ocidental do mundo. No Brasil, mais de $60 \%$ da população ${ }^{1}$ teria acesso à plataforma. Os estudos sobre o uso do Facebook como espaço de debate, consulta ou persuasão política são inúmeros, com relatos e experimentos sobre potenciais midialivristas (MALINI, 2015), conectividade em rede de grupos ativistas (ALVES, 2016; PENTEADO e LERNER, 2018), influência algorítmica (SILVEIRA, 2019) e muitos outros. Braga e Carlomagno (2018, p.21) identificam no pleito de 2012 um ponto de virada na comunicação eleitoral, quando a principal inovação foi o uso do Facebook "por alguns candidatos outliers que utilizaram intensamente a ferramenta como instrumento de mobilização e agendamento de campanha, embora o debate aprofundado sobre políticas públicas estivesse ausente da plataforma". Nos dois pleitos seguintes, a plataforma se consolidou como mídia digital hegemônica e fonte de medição de reações a fatos, eventos políticos ou testes de campanhas.

1 TECMUNDO. Brasil é o terceiro país com mais usuários no Facebook. 2019. Disponível em: <https://www.tecmundo.com.br/redes-sociais/139130-brasil-terceiro-pais-usuarios-facebook.htm>. 


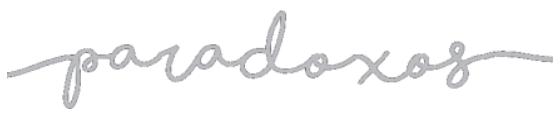

Práticas vernaculares de moderação Online em grupos do Facebook

SILVA, 2020

Essa hegemonia da plataforma Facebook na comunicação político-eleitoral e em outras esferas comunicativas do cotidiano leva a perguntas sobre as interações entre a plataforma e a construção - ou erosão - de comportamentos coletivos. Pereira (2019) apresenta desafios nos espaços de conversação digitais que variam de acordo com contextos quanto a tamanho e abertura dos ambientes. Quando há poucos participantes e limitação do acesso, haveria uma tendência a manter o foco nas discussões sem muitas disrupções. No entanto, espaços de interação digitais com poucas barreiras de entrada e muitos participantes seriam locais afeitos a perturbações, tais como trolling e flaming.

Uma vez que ambientes como Facebook são suporte de gigantescas comunidades de interesse nos mais diversos temas, será que são elaboradas táticas emergentes de organização dos grupos? E estas táticas possuem alguma similaridade com táticas propostas por pesquisadores e designers de espaços institucionais de deliberação?

\section{Grupos do Facebook: experiência vernacular de moderação}

Nos baseamos na ideia de que a "web 2.0" (e desenhos posteriores de compreensão da comunicação mediada por computador) seria espaço próprio da “sociologia vernacular". Para David Beer e Roger Burrows (2007, s.p., trad. livre), os sites de redes sociais em particular revelam uma "tendência sociológica em usuários web na medida em que buscam e navegam através de perfis de seus pares "wiki-cidadãos", lendo sobre eles, olhando suas fotografias e assim por diante”. Este engajamento através de uma "sociologia vernacular" não seria exatamente novo, mas a ampla possibilidade de pesquisa informacional de caráter extrativo demonstra "um interesse contínuo nas vidas mundanas de outras pessoas" (2007, s.p., trad. livre) e poderia ser visto como algo potencialmente positivo para a sociabilidade contemporânea.

Mas, para além da busca por informações e observação de comportamento e de outros cidadãos e seus padrões decorrentes, acreditamos que os usuários de ambientes digitais de interação podem exercitar práticas de organização da conversação online.

Dado o apresentado anteriormente, realizamos uma exploração que busca responder a seguinte pergunta: as práticas vernaculares de definição de regras em grandes grupos do Facebook possuem similaridades com as características e categorias identificadas por estudiosos da moderação online em contextos políticos? 
Através da página de Grupos no Facebook ${ }^{2}$, navegamos por três das categorias principais oferecidas na plataforma: "Animais", "Comida \& Bebida" e "Viagens". A escolha dessas três categorias se justifica por se tratarem de campos de interesse sujeitos a despertar engajamento de virtualmente qualquer pessoa conectada.

Entre os 50 grupos exibidos em cada uma das categorias, selecionamos os 5 grupos de maior número de membros ${ }^{3}$, resultando na lista apresentada na Tabela 01.

Tabela 01: Grupos do Facebook analisados

\begin{tabular}{|c|c|c|c|}
\hline Categoria & Nome do Grupo & Membros (000) & Url \\
\hline Animais & Adoro gatos (felinos) & 543 & https://www.facebook.com/groups/adorogatosfelinos \\
\hline Animais & Grupo Eu amo os animais & 431 & https://www.facebook.com/groups/188547568257314/ \\
\hline Animais & Cavalo uma Paixão & 364 & https://www.facebook.com/groups/838419549631454 \\
\hline Animais & Adoro Cachorros & 204 & https://www.facebook.com/groups/180647998645647 \\
\hline Animais & DOAÇÃO DE ANIMAIS & 201 & https://www.facebook.com/groups/797382623632285 \\
\hline Comida \& Bebida & Churrasqueadas & 399 & https://www.facebook.com/groups/2158234304191976/ \\
\hline Comida \& Bebida & Churrasco & 136 & https://www.facebook.com/groups/235622249848473 \\
\hline Comida \& Bebida & $\begin{array}{l}\text { DOCES, BOLOS E } \\
\text { BOMBONS }\end{array}$ & 125 & https://www.facebook.com/groups/161963403928327 \\
\hline Comida \& Bebida & Veganismo Popular & 37 & https://www.facebook.com/groups/455365031301022 \\
\hline Comida \& Bebida & Doceiras Apaixonadas & 22 & https://www.facebook.com/groups/361844064202313 \\
\hline Viagens & Morar em Portugal - Grupo & 158 & https://www.facebook.com/groups/1556148624646811 \\
\hline Viagens & $\begin{array}{l}\text { Mochileiros (Grupo } \\
\text { Fechado) }\end{array}$ & 126 & https://www.facebook.com/groups/229895393761607 \\
\hline Viagens & $\begin{array}{l}\text { Lugares Que Eu Gostaria } \\
\text { De Ir - VIAJANTES }\end{array}$ & 117 & https://www.facebook.com/groups/1892308367722506 \\
\hline Viagens & Brasileiros em Portugal & 114 & https://www.facebook.com/groups/1625000164471806 \\
\hline Viagens & Desbrave o Mundo & 96 & https://www.facebook.com/groups/234151230298089 \\
\hline
\end{tabular}

Fonte: Elaborada pelo autor, a partir de dados coletados em 01/09/2019.

Sampaio, Barros e Morais (2012) apresentam levantamento de critérios identificados pela literatura acadêmica na avaliação de iniciativas de deliberação online. A partir de 59 trabalhos, foram identificados 229 códigos diferentes, posteriormente

\footnotetext{
2 https://www.facebook.com/groups/.

${ }^{3}$ Como filtro adicional, excluímos os grupos vinculados apenas a atividades comerciais em cada um dos campos selecionados. Coleta de dados realizada em julho de 2019.
} 
agrupados pelos autores em oito grupos: justificação racional; reciprocidade; sinceridade; pluralidade; reflexividade; respeito; igualdade; informação; e tópico.

Figura 1: Categorias de análise de deliberação online

\begin{tabular}{|l|c|}
\hline \multicolumn{1}{|c|}{ CATEGORIA } & QUANT. \\
\hline 1) justificação & 83 \\
\hline 2) reciprocidade & 81 \\
\hline 3) pluralidade & 63 \\
\hline 4) reflexividade & 56 \\
\hline 5) respeito & 31 \\
\hline 6) igualdade & 21 \\
\hline 7) informação & 10 \\
\hline 8) tópico & 8 \\
\hline 9) outro & 16 \\
\hline
\end{tabular}

Fonte: Sampaio, Barros e Morais, 2012

Os autores descrevem os códigos e enfatizam que podem ser úteis para estudos em outros ambientes digitais que não busquem necessariamente um fim deliberativo ou democrático. Para estes outros fins, seriam demasiadamente exigentes, mas "representam princípios importantes para discussões razoáveis, especialmente, quando se trata de tarefas que exigem compromisso, colaboração e respeito entre os participantes" (SAMPAIO, BARROS e MORAIS, 2012, p.483).

Deste modo, surge uma primeira pergunta sobre os grupos selecionados na amostra: eles apresentam regras de forma explícita? Identificamos que todos os grupos de fato incluem ao menos regras de convívio, postagem e proibições em diferentes formatos. Geralmente (11 de 15 grupos), as regras são exibidas na Descrição do Grupo ou em uma Postagem fixada para que todos os membros possam ver. A plataforma Facebook adicionou um recurso explícito para inclusão de regras apenas em agosto de $2018^{4}$ - uma das inúmeras funcionalidades que foram originalmente adaptadas de práticas já existentes no ambiente digital. Os administradores podem adicionar regras numeradas que ganham destaque adicional, como podemos ver na Figura 2. Nesta, estão quatro regras que são oferecidas como exemplo pela própria plataforma. Apenas 2 dos 15 grupos usaram apenas estas regras - a ampla maioria criou as suas próprias.

\footnotetext{
${ }^{4}$ Disponível em: <https://www.facebook.com/community/education/blog/group-rules/>. 
Figura 2: Exemplo de Caixa de Regras em Grupo do Facebook

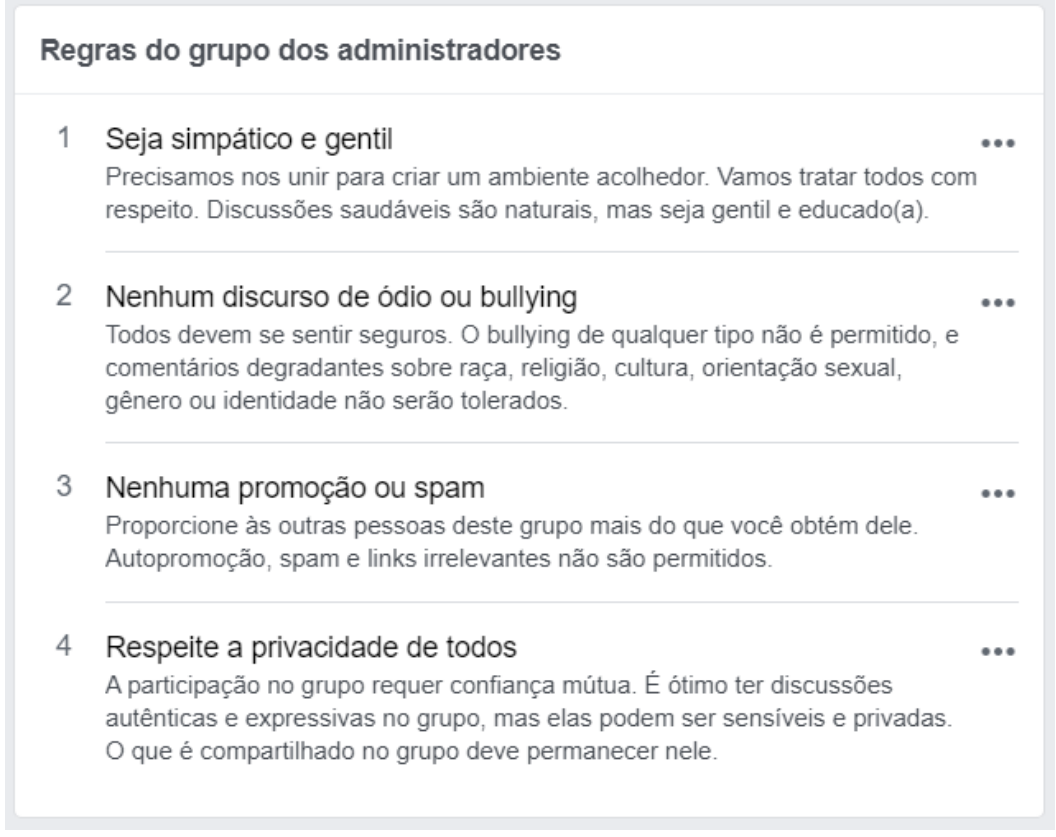

Fonte: Captura de Tela realizada pelo autor, a partir de https://www.facebook.com/groups.

O número total de regras explícitas, entretanto, variou de 4 a 17 regras, com a média de 8 por grupo. Considerando a extração de todos os textos de regras dos grupos, ideamos categorias parcialmente a partir de classificação fundamentada nos dados (TAROZZI, 2011) e direcionada pela busca das categorias propostas por Sampaio, Barros e Morais (2012), com o objetivo de identificar quais valores de convívio são recomendados, práticas de moderação explicitadas e quais práticas são proibidas, incluindo punições cabíveis.

Duas categorias propostas pelos autores foram identificadas como diretamente adaptáveis ao estudo de práticas de moderação em outras esferas sociais: Tópico e Respeito. Durante a análise, outras categorias relevantes foram identificadas que, por sua vez, dão pistas de recomendações técnicas em espaços digitais deliberativos.

Adequação ao Tópico é a mais presente entre as categorias diretamente ligadas à proposição da Deliberação Online. Sampaio (2012, p.481) e colaboradores argumentam que "não é um elemento inerente aos critérios da deliberação, mas é, provavelmente, o único que considera o ambiente online". Com grupos de 23 a 543 mil usuários, a regra está presente de forma explícita em 9 dos 15 grupos analisados (60\% dos grupos). As características das plataformas de mídias sociais de baixo esforço na publicação e criação 


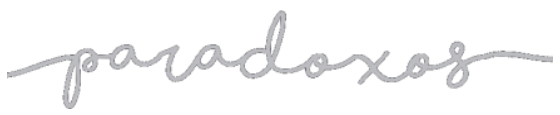

Práticas vernaculares de moderação Online em grupos do Facebook

SILVA, 2020

de conteúdos parecem justificar tecnicamente a exigência, uma vez que a descaracterização efetiva do conteúdo de uma determinada comunidade é tarefa relativamente fácil e pode gerar um efeito bola de neve de desengajamento.

O Respeito entre os participantes como valor a ser levado em conta foi identificado também nas regras propostas pelos administradores do grupo. $\mathrm{Na}$ bibliografia sobre deliberação, "este critério se manifesta no respeito pelos argumentos do outro, respeito a grupos e minorias e manutenção de uma atmosfera de grupo que busca o entendimento comum" (SAMPAIO, BARROS e MORAIS, 2012, p. 481); nos textos do grupo, encontramos conceitos análogos de forma propositiva e de forma restritiva. No polo propositivo, 6 de 15 grupos propõem explicitamente que as pessoas mantenham Cordialidade ou gentileza. Foi curioso observar que 2 dos 6 grupos com critério propositivo de cordialidade apenas replicaram o texto padrão do Facebook: "Seja simpático(a) e gentil. Precisamos nos unir para criar um ambiente acolhedor. Vamos tratar todos com respeito. Discussões saudáveis são naturais, mas seja gentil e educado(a)”. Muito mais frequente, porém, o critério da manutenção do Respeito esteve presente como proibição explícita sobre ofensas, agressividade e xingamentos (13 de 15). Como podemos ver na Figura 3, a proibição de ofensas foi a regra mais frequente, seguida por proibição de propaganda e posts comerciais, foco no tópico e restrições específicas (que veremos a seguir).

Figura 3: Exemplo de Caixa de Regras em Grupo do Facebook

\section{Regras de Moderação - Grupos do Facebook} 15

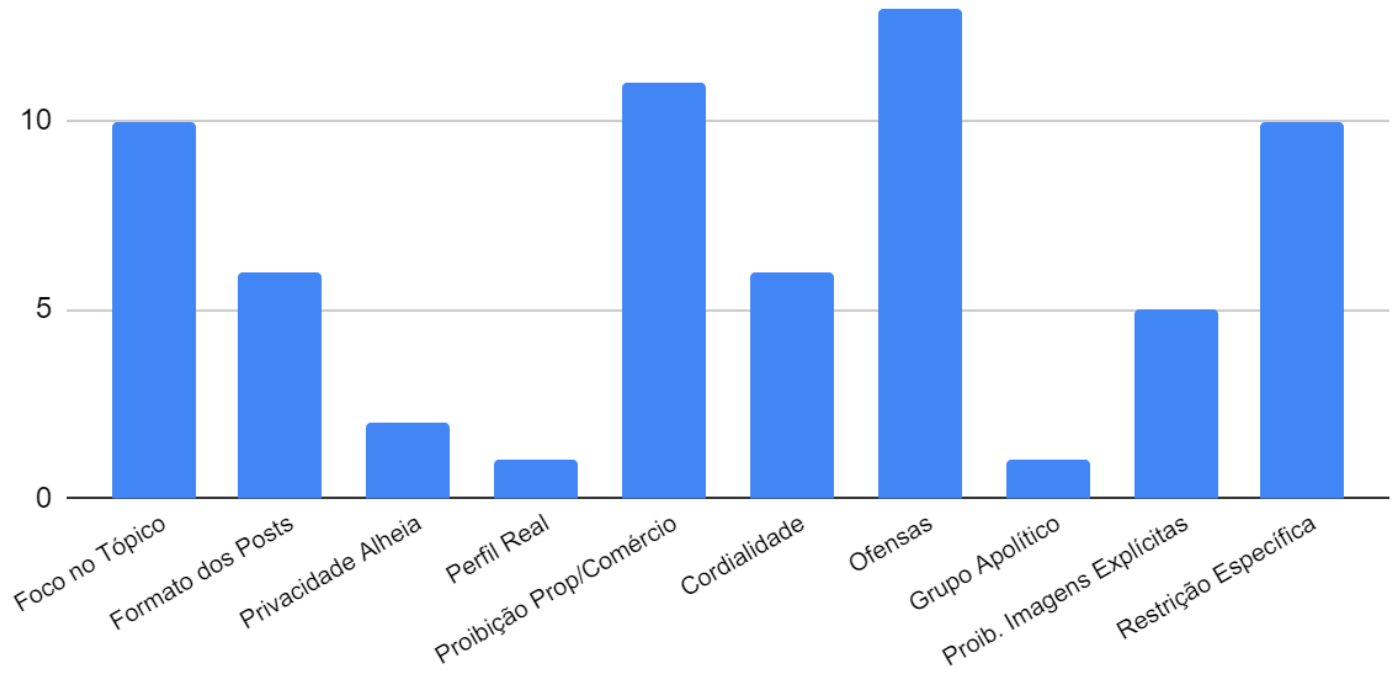

Fonte: Elaborado pelo autor. 
A comunalidade (ERTAS et al., 2019) entre os membros dos grupos é citada indiretamente através dos objetivos em comum ligados a informação, entretenimento e sociabilidade. Expressões como "troca de informações", "propósito recreativo", “informações, novidades e troca de experiência" são declaradas em parte das regras. Entretanto, a busca por um "entendimento comum" não é presente, pois os grupos não pretendem consensos deliberativos ou discursivos.

O apelo democrático da moderação coletiva é valorizado no campo da deliberação, mas a dificuldade de implementação também é apresentada, como alega Pereira (2019, p. 7): "a moderação individual acaba por ser menos democrática, pois as decisões ficam nas mãos de apenas uma pessoa, mas também pode ser mais eficiente". O autor apresenta a ideia de moderação distribuída, o que, de certa forma, está presente em potência nos grupos do Facebook, uma vez que o recurso de Denúncia aos Moderadores é padrão.

Dissenso em questões essenciais valorizadas pelos administradores é tratado como algo a ser evitado em alguns grupos, chegando a um alto grau de "posicionamento" sobre questões controversas de acordo com a crença dos criadores dos grupos. Na amostra de grupos analisados, dois deles se destacaram nesta questão: Veganismo Popular e Adoro Gatos (Felinos). Enquanto a extensão do texto das regras dos demais grupos é de 895 caracteres em média, estes dois grupos possuem textos de regras com respectivamente 5.133 e 5.523 caracteres. A discrepância é resultado da declaração de posicionamentos sobre questões controversas quanto a criação de gatos domésticos e sobre o que seria um veganismo popular e accessível.

O grupo Adoro Gatos (Felinos) estabelece 17 regras ao todo, especificando desde como adicionar informações em postagens sobre doações de gatos a formato de fotos. Ao tratar de controvérsias, porém, os administradores redigem obrigações que declaram uma posição e proíbem as demais; por exemplo, "[o] grupo é a favor da castração, pois a castração evita doenças, acaba com a agressividade, com os borrifamentos territoriais, e as ninhadas indesejadas!”. O mesmo acontece sobre a proibição de falar sobre medicamentos e perguntas sobre o sexo do animal, para evitar problemas com os animais, uma vez que o ideal é a consulta veterinária.

Deixar o gato sair de casa, chamado de "voltinha", é outra controvérsia. Enquanto parte dos tutores acredita que deixar o animal sair de casa respeita sua liberdade e autonomia para uma vida plena, outros acreditam que o mais importante é evitar os inúmeros riscos relacionado 
à essa prática - como agressões, doenças, atropelamentos etc. Os administradores do grupo deixam claro que o ambiente não deve tratar do assunto e que são contra.

Um formato específico de publicação regulamentado é a chamada "Nota Estrelinha", postagens sobre falecimento do felino, realizadas pelos tutores para informar aos amigos online e receber condolências. A regra enfatiza que não se deve publicar foto do animal morto nem do motivo da morte, para evitar críticas e responsabilização do tutor, o que desembocaria em disrupção do grupo.

O caso do Veganismo Popular é ainda mais interessante, pois se trata da busca de um ideal "popular" do veganismo para que alcance o máximo número de pessoas. As práticas veganas seriam frequentemente taxadas, por diferentes motivos, de elitistas. O grupo busca combater na prática esta crença por meio do fornecimento de informações e receitas. $\mathrm{Na}$ descrição, as administradoras declaram que "Nossa ideia é mostrar o lado fácil, rápido e barato da alimentação dos veganos. Afinal, no dia a dia, como você deixa suas refeições libertas de exploração, conciliando com trabalho elou estudos e gastando o mínimo possível?".

Assim como o grupo citado anteriormente, Veganismo Popular também lista 17 regras relacionadas a aderência ao tópico, respeito entre membros, formato de publicações e outras. A grande ênfase está no caráter popular e acessível da alimentação, como apontam as administradoras ao dizer que "o foco do grupo é postagem de refeições $100 \%$ vegetais $e$ populares, seguindo a definição de popular como o que é de fácil acesso e possível de ser adquirido pela maior parte das pessoas". Na prática da moderação, isto se desdobra em uma lista de alimentos não permitidos. Ao todo, 44 alimentos são listados, tais como pistache, goma xantana e macadâmia; estes produtos não podem ser postados ou sugeridos, uma vez que estão indisponíveis para a maior parte da população brasileira por questões econômicas.

A partir da pesquisa realizada, podemos confirmar a recomendação de Sampaio e colaboradores (2012) de que a literatura sobre critérios de deliberação online é útil para pensarmos outros espaços de conversação pública. Para além disto, a exploração das regras dos grupos selecionados mostrou-nos que práticas de moderação se adaptam ao contex to temático de cada comunidade assim como nas affordances das plataformas. A conversação e debate público em grupos do Facebook se demonstram como espaços de articulação e reflexão pública, em que criadores e administradores de comunidades realizam práticas vernaculares de observação das dinâmicas sociais e operacionalizam modos e regras para promover ou manter ambientes que julgam como positivos para seus objetivos informacionais e de entretenimento. 


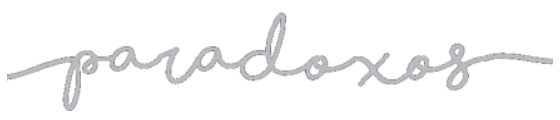

Práticas vernaculares de

moderação Online em grupos do Facebook

SILVA, 2020

\section{Conclusões}

No presente artigo, exploramos conceitos relacionados aos critérios analisados como pertinentes na avaliação de iniciativas de deliberação online, a partir de revisões de literatura disponíveis. Especificamente sobre a questão da moderação, buscamos discorrer sobre uma questão/hipótese de equivalência de alguns dos fatores relevantes para a deliberação em relação a práticas vernaculares de moderação e construção de regras em grupos não-deliberativos no Facebook.

Pudemos observar que apenas dois critérios claramente se equivalem, notadamente aderência ao Tópico de Discussão e Respeito. Outros critérios não estão presentes nestes grupos, uma vez que não buscam um consenso claro ou deliberação sobre tema público. Ao contrário, parte relevante das regras busca evitar completamente o dissenso seja a partir da recusa às citações de controvérsias seja pela definição clara de posicionamento prévio.

Entretanto, diversas regras específicas dos grupos podem ser vistas como relevantes para a manutenção das trocas positivas e cidadania nos ambientes digitais. Estudos futuros e desdobramentos poderão buscar aprofundamento das primeiras observações exploratórias a partir das hipóteses levantadas. Os grupos apresentam outras dinâmicas de manutenção de qualidade das trocas informacionais e lúdicas, como evitação de conflito, proibição de uso apenas comercial da comunidade, adequação das colaborações a formatos óptimos entre outros. Acreditamos que as práticas de moderação são resultado de uma percepção vernacular da sociedade, em consonância com a crença de que a exposição frequente a conteúdos múltiplos e multimodais de outros grupos apoia o desenvolvimento de táticas de mediação da alteridade.

\section{Referências}

ALVES, Marcelo. Campanha não oficial-A Rede Antipetista na eleição de 2014. Fronteiras-estudos midiáticos, v. 19, n. 1, p. 102-119, 2016.

BEER, David; BURROWS, Roger. Sociology and, of and in Web 2.0: Some initial considerations. Sociological research online, v. 12, n. 5, p. 67-79, 2007.

BOYD, Danah. Social network sites as networked publics: Affordances, dynamics, and implications. In: PAPACHARISSI, Z. (org.). A Networked Self: Identity, community, and culture on social network sites. Routledge, 2010. p. 47-66. 
BRAGA, Sérgio; CARLOMAGNO, Márcio. Elections as usual? longitudinal analysis of the changes caused by digital technologies in Brazilian electoral campaigns (1998-2016). Revista Brasileira de Ciência Política, n. 26, p. 7-62, 2018.

CHADWICK, Andrew; DENNIS, James; SMITH, Amy P. Politics in the age of hybrid media: Power, systems, and media logics. In: BRUNS, A.; ENLI, G.; SKOGERBO, E.; LARSSON, A. O.; CHRISTENSEN, C. (orgs.). The Routledge companion to social media and politics. Routledge, 2015. p. 7-22.

ERTAS, Hulya; PAK, Burak; NEWTON, Caroline. An Operational Framework for an Online Community Based on the Commons, Dissensus and Shared Knowledge. Postdigital Science and Education, p. 1-19, 2019.

GOMES, Wilson. Esfera Pública e Comunicação Política. Aula do curso Opinião Pública e Política: Deliberação Online. Circulação restrita. INCT, 2019.

HELMOND, Anne. The platformization of the web: Making web data platform ready. Social Media + Society, v. 1, n. 2, p. $2056305115603080,2015$.

MALINI, Fabio. Literatura, Twitter e Facebook: A economia dos likes e dos rts dos usuários-fãs de literatura brasileira nas redes sociais. Revista Observatório Itaú Cultural, v. 17, p. 204-233, 2014.

PENTEADO, C.; ARAÚJO, R; PIMENTEL, M. Sociedade Civil e Políticas Públicas: o uso da Internet pela Rede Nossa São Paulo na Articulação Política. In: SILVEIRA, S.;

BRAGA, S.; PENTEADO, C. Cultura, política e ativismo nas redes digitais. São Paulo: Editora Fundação Perseu Abramo, 2014.

PENTEADO, Claudio Luis de Camargo; LERNER, Celina. A direita na rede: mobilização online no impeachment de Dilma Rousseff. Em Debate, Belo Horizonte, v.10, n.1, p.12-24, abril 2018.

PEREIRA, Marcus Abílio. Moderadores e Deliberação. Aula do curso Opinião Pública e Política: Deliberação Online. Circulação restrita. INCT, 2019.

SAMPAIO, Rafael C.; BARROS, Chilani TG. Internet como esfera pública? Análise de usos e repercussões reais das discussões virtuais. Estudos em Comunicação/Communication Studies, v. 9, p. 161-183, 2011.

SAMPAIO, R. C.; BARROS, S. A. R.; MORAIS, R. Como avaliar a deliberação online?: um mapeamento de critérios relevantes. Opinião Pública, v. 18, p. 470-489, 2012.

SILVEIRA, Sérgio Amadeu da. Tudo sobre Tod@s: redes digitais, privacidade e venda de dados pessoais. São Paulo: Edições Sesc, 2017.

SILVEIRA, Sérgio Amadeu da. Democracia e os Códigos Invisíveis. São Paulo: Edições Sesc, 2019.

TAROZZI, Massimiliano. O que é a Grounded Theory. Metodologia de pesquisa e de teoria fundamentada nos dados. Petrópolis-RJ: Vozes, 2011. 